\title{
Emerging Data on the Safety and Efficacy of Transurethral Water Vapour Therapy for Benign Prostatic Hyperplasia
}

\author{
Patrick Jones (iD) ${ }^{1,2}$ \\ Giampaolo Siena ${ }^{3}$ \\ BM Zeeshan Hameed ${ }^{2,4}$ \\ Bhaskar K Somani iD ${ }^{2,5}$ \\ 'Department of Urology, Haukeland \\ University Hospital, Bergen, Norway; \\ ${ }^{2} E A U$ Young Academic Urology \\ Urolithiasis and Endourology Working \\ Party, Arnhem, Netherlands; \\ ${ }^{3}$ Department of Urology, Careggi \\ University Hospital, Florence, Italy; \\ ${ }^{4}$ Kasturba Medical College Manipal, \\ Manipal Academy of Higher Education, \\ Manipal, Karnataka, India; ${ }^{5}$ Department \\ of Urology, University Hospital \\ Southampton, Southampton, UK
}

\begin{abstract}
Benign prostate disease is a disease of prevalence and over $25 \%$ of men affected by bothersome lower urinary tract symptoms (LUTS) as a result of it will require surgical intervention during their lifetime. While transurethral resection of the prostate (TURP) has served as the cornerstone treatment for many years, there now exist a multitude of minimally invasive alternatives including the Rezum system. The latter is a novel form of transurethral water vapour therapy, which is attracting increasing attention. It utilizes convective water vapour energy (WAVE) and thereby radiofrequency (RF) in order to generate heat energy. Early studies have demonstrated promising results. To date there have been 12 studies published on Rezum, however only one randomized trial. This review offers an overview and evaluation of this emerging evidence.
\end{abstract}

Keywords: Rezum, BPH, prostate, benign prostatic hyperplasia, minimally invasive surgery

\section{Introduction}

Benign prostatic hyperplasia (BPH) is a disease of prevalence and its natural history renders $25 \%$ of men to be affected by bothersome lower urinary tract symptoms (LUTS) caused by bladder outflow obstruction during their lifetime. ${ }^{1,2}$ The sequelae are far reaching and can significantly affect their quality of life. ${ }^{3}$ In cases refractory to conservative and medical treatments, surgery represents the next step in the management pathway. While transurethral resection of the prostate (TURP) has served as the cornerstone treatment for many years, there now exist a multitude of minimally invasive alternatives, which achieve effect through a range of mechanisms of action. ${ }^{4}$ For example, prostatic urethral lift and iTIND rely principally on mechanical decompression whereas prostate artery embolization (PAE) induces glandular ischemia. ${ }^{5,6,7}$ In order to achieve general uptake, new treatment modalities are required to demonstrate sufficient improvement across both objective and subjective outcome measures as well as maintaining a strong safety profile. Improvements should be durable and sustained at long term follow up while striving to adhere to a favorable financial model.

The Rezum system is a novel device, which utilizes convective water vapour energy (WAVE) and thereby radiofrequency (RF) in order to generate heat energy. ${ }^{8}$ Large volumes of stored energy $\left(540 \mathrm{cal} / \mathrm{mL} \mathrm{H}_{2} \mathrm{O}\right)$ are released when the water vapour (approx. $103^{\circ} \mathrm{C}$ ) makes contact with the tissue and subsequent condensation occurs. Cell necrosis ensues as a result of temperature change. Through use of these
Correspondence: Patrick Jones Department of Urology, Haukeland University Hospital, Bergen, Norway $\mathrm{Tel} / \mathrm{Fax}+447950050667$

Email patrick.jones I@nhs.net 
steam injections, transurethral delivery of this energy can be targeted with precision and overlapping lesions are formed in the desired anatomical location. While still relatively new, early studies have demonstrated promising results and it obtained approval by the US Food and Drug Administration (FDA) in 2015 and the National Institute for Health and Care Excellence (NICE) guidelines in 2018. ${ }^{9}$ While there has been an increasing amount of emerging data on Rezum, critical evaluation of its safety and efficacy remains under-reported. This review therefore aimed to deliver such an appraisal and provide an overview of its current status.

\section{Methods}

A comprehensive review of world literature was performed in order to find original studies on Rezum. Bibliographic databases searched included Medline, Google Scholar, Cochrane database and center for trials. All study types were considered eligible as long as full text articles were available in English language, and the search was completed in January 2021.

\section{Rezum}

To date there have been 12 studies published on Rezum, which have included 1391 patients (mean age 68.7 years, range: 46-90) (Tables 1 and 2). ${ }^{9-20}$ Over half of these studies $(n=7)$ have been published in the past 2 years, reflecting the increasing interest and uptake of this novel intervention. There has only been one randomized study and the remainder represent cohort studies (5x retrospective and $6 \times$ prospective). Seven of these studies were performed in a multi-center setting. ${ }^{10-12,14,17,18}$ The randomized study used a sham procedure as a comparator.-

${ }^{14}$ This consisted of rigid cystoscopy with simulated active treatment sound effects. Across the studies, the mean prostate volume was $61.6 \mathrm{cc}$ (range: 19.5-183). The mean number of steam injections administered was 6.5 (range: 4-10) in the seven studies, which reported this. ${ }^{9,13,14,18,19}$ Duration of follow up ranged from 1 week (proof of concept study) to 5 years. ${ }^{9,14}$ Selection criteria for studies are summarized in Table 3 .

\section{Efficacy}

In 2020, a Cochrane review was published on this technology, however it only considered data from one study, the randomized trial. ${ }^{14,21}$ The heterogeneity of parameters reported among published studies and wide range of follow up periods preclude formal meta-analysis in previous and current study. However, consistent improvements in clinical outcomes after Rezum can be observed across all the studies.

Eight of the studies reported on change in international prostate symptom score (IPSS) and each of these revealed improvements (Table 4). ${ }^{11-16,19,20}$ In their prospective single center study of 210 patients, Johnston et al recorded mean improvement in IPSS of $78.5 \%$ after 12 months (20.4 vs 4.3, $\mathrm{p}<0.001$ ) and mean improvement of $97.5 \%$ in maximum urinary flow rate (Qmax) of $97.5 \%$ (9.2 vs $18.2 \mathrm{~mL} / \mathrm{s}, \mathrm{p}<0.001$ ) over the same time period. ${ }^{16}$ These changes represent the most pronounced across all reported studies. Other studies have recorded at least 30\% improvement in IPSS and McVary et al reported a mean change of $-48 \%$ at the five year follow up assessment $(<0.001){ }^{14}$ This improvement had been stable since the 12 month follow up assessment when the mean improvement recorded was $52.2 \%(\mathrm{p}<0.001)$. This was mirrored in the results for Qmax, where mean improvement was 49\% (9.9 vs $14, \mathrm{p}<0.001)$ after five years. Quality of life $(\mathrm{QoL})$ data were reported by only four studies, however these all demonstrated improvement. ${ }^{11,12,14,16}$ Mean change in QoL scores ranged from $37.8 \%$ to $72 \%$. Again, in the five year follow up study of the randomized trial, the result had plateaued and remained largely similar since the initial 12-month assessment (45\% improvement). ${ }^{14}$ Dixon et al also reported a statistically significant mean improvement in QoL at two year follow up (4.4 vs $1.8, \mathrm{p}<0.001) .{ }^{11}$

As well as the advantage of Rezum in treating patients with an obstructing median lobe, this intervention may offer the potential to become a standard treatment for patients with large prostate burden. While Rezum is acknowledged in the European Association of Urology (EAU) guidelines as a new intervention in the surgical management of $\mathrm{BPH}$, it has yet to receive any formal recommendation. ${ }^{2}$ However, NICE recommends its application only in the setting of prostate size between 30 $80 \mathrm{cc}^{8}{ }^{8}$ Two studies specifically analyzed the feasibility of Rezum in larger prostate size $(>80 \mathrm{cc}) .{ }^{15,19}$ Bole et al reported statistically significant improvements in IPSS (22 vs 13.4, p=0.04), post void residual (PVR) (305 vs $149 \mathrm{~mL}, \mathrm{p}=0.05)$, and $\operatorname{Qmax}(7.7 \mathrm{vs} 12.7 \mathrm{~mL} / \mathrm{s}, \mathrm{p}=0.002)$ in a patient group (mean prostate volume 119cc). ${ }^{15}$ Furthermore, $55.3 \%$ were catheter dependent preoperatively. The application of Rezum in catheter dependent patients with complete urinary retention would be a further advantage. In 2020, McVary et al reported findings from a registry of patients $(n=38)$ with this clinical 


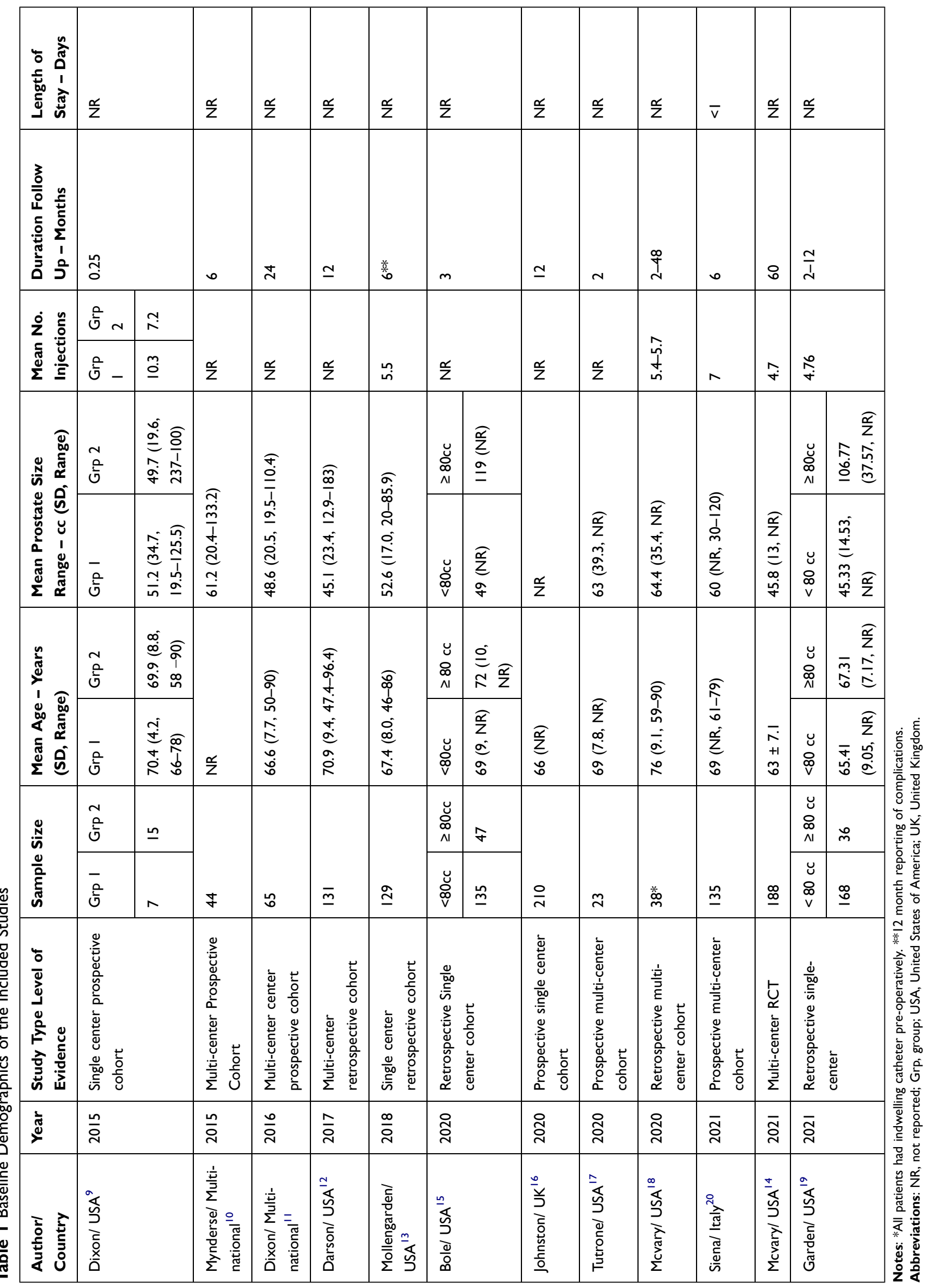


Table 2 Additional Characteristics

\begin{tabular}{|c|c|c|c|c|c|c|c|c|c|c|}
\hline Author & \multicolumn{2}{|c|}{$\begin{array}{l}\text { Catheter Pre op } \\
\text { (\%) }\end{array}$} & \multicolumn{2}{|c|}{ Mean IPSS } & \multicolumn{2}{|c|}{$\begin{array}{l}\text { Mean Qmax } \\
(\mathrm{mL} / \mathrm{s})\end{array}$} & \multicolumn{2}{|c|}{ Mean QoL } & \multicolumn{2}{|c|}{$\begin{array}{l}\text { Catheter Post op (\%)/Time to } \\
\text { Removal/ Duration (Days) }\end{array}$} \\
\hline Dixon 9 & \multicolumn{2}{|l|}{ NR } & \multicolumn{2}{|l|}{23.6} & \multicolumn{2}{|l|}{7.7} & \multicolumn{2}{|l|}{4.1} & \multicolumn{2}{|l|}{ NR/NR } \\
\hline Mynderse ${ }^{10}$ & \multicolumn{2}{|l|}{ NR } & \multicolumn{2}{|l|}{ NR } & \multicolumn{2}{|l|}{ NR } & \multicolumn{2}{|l|}{ NR } & \multicolumn{2}{|l|}{ NR } \\
\hline Dixon"I & \multicolumn{2}{|l|}{$N R$} & \multicolumn{2}{|l|}{21.66} & \multicolumn{2}{|l|}{7.9} & \multicolumn{2}{|l|}{4.3} & \multicolumn{2}{|l|}{$55 / 4.1^{*}$} \\
\hline Darson $^{12}$ & \multicolumn{2}{|l|}{ NR } & \multicolumn{2}{|l|}{19.5} & \multicolumn{2}{|l|}{8.6} & \multicolumn{2}{|l|}{4.3} & \multicolumn{2}{|l|}{ NR } \\
\hline Mollengarden ${ }^{13}$ & \multicolumn{2}{|l|}{ NR } & \multicolumn{2}{|l|}{18.3} & \multicolumn{2}{|l|}{10.5} & \multicolumn{2}{|l|}{ NR } & \multicolumn{2}{|l|}{$65.1 / 4.4$} \\
\hline \multirow[t]{2}{*}{ Bole $^{15}$} & $<80 \mathrm{cc}$ & $\geq 80 \mathrm{cc}$ & $<80 \mathrm{cc}$ & $\geq 80 \mathrm{cc}$ & $<80 \mathrm{cc}$ & $\geq 80 \mathrm{cc}$ & $<80 \mathrm{cc}$ & $\geq 80 \mathrm{cc}$ & $<80 \mathrm{cc}$ & $\geq 80 \mathrm{cc}$ \\
\hline & 25.2 & 55.3 & 22.1 & 22 & 9.2 & 7.7 & NR & NR & 12/Minimum 3 days & $|7 / 3-4|$ \\
\hline Johnston ${ }^{16}$ & \multicolumn{2}{|l|}{11.9} & \multicolumn{2}{|l|}{20.4} & \multicolumn{2}{|l|}{9.2} & \multicolumn{2}{|l|}{4.3} & \multicolumn{2}{|l|}{$100 / 3-5$} \\
\hline Tutrone $^{17}$ & NR & & 15.6 & & NR & & 2.5 & & $87 / 4.5$ & \\
\hline Mcvary ${ }^{18}$ & 100 & & NR & & NR & & NR & & $100 / 26.6$ & \\
\hline Siena ${ }^{20}$ & NR & & 21.5 & & 8.1 & & NR & & $100 / 7 *$ & \\
\hline Mcvary $^{14}$ & NR & & 16.3 & & 9.2 & & 3.9 & & NR & \\
\hline Garden ${ }^{19}$ & $<80 \mathrm{cc}$ & $\geq 80 \mathrm{cc}$ & $<80 \mathrm{cc}$ & $\geq 80 \mathrm{cc}$ & $<80 \mathrm{cc}$ & $\geq 80 \mathrm{cc}$ & $<80 \mathrm{cc}$ & $\geq 80 \mathrm{cc}$ & $100 / 3-7$ & \\
\hline & 5.95 & 22.2 & 16.6 & 15.2 & 9.5 & 7.4 & NR & NR & & \\
\hline
\end{tabular}

Note: *Median.

Abbreviations: IPSS, international prostate symptom score; Qmax, maximum urinary flow rate; NR, not reported.

profile. ${ }^{18} 73 \%$ of these patients achieved a catheter free status and the median length of time to achieve this was 26 days (range: 4-65) after the procedure.

\section{Safety}

The most common low-grade complications (Clavien <2) associated with this intervention are urinary tract infection (UTI), urinary retention, hematuria and new onset bothersome lower urinary tract symptoms such as frequency and urgency. As demonstrated in Table 5, there is a range of these reported low-grade complications. Garden et al reported that hematuria, urgency, and frequency occurred in $39.29 \%, 30.36 \%$, and $30.95 \%$ of patients respectively. ${ }^{19}$ In the randomized trial performed by McVary et al, this same group of bothersome symptoms was also captured, albeit with lower rates. ${ }^{14}$ In contrast, in other studies no such bothersome symptoms were reported. Given that many patients do experience such self-resolving bothersome symptoms of this nature, similar to the post PAE syndrome, these symptoms may not have been captured in some studies as patients presented to primary care or their symptoms resolved in time. ${ }^{22}$ Most studies recorded rates of UTI between $10-20 \%$. Similar to other adverse events such as dysuria and hematuria, a main reason for this is considered to be due to both the catheter being left in situ 5-7 days after the procedure and the necrotic tissue produced after the procedure. Increasingly therefore, a short course of antibiotics is recommended as part of the post intervention care plan. Rates of urinary retention varied from zero cases in some studies to as high as $33.8 \%{ }^{11}$ Given the limited number of studies which have been performed using Rezum, this may be part of the evolution of patient selection for this procedure as the optimal candidate is being determined as well as the expected learning curve for centers newly adopting the technique. Inclusion criteria also varied across the studies, which also likely contributed to this. For example, Darson et al left patient selection to the discretion of the clinician whereas stricter measures were followed in other studies. ${ }^{12}$

Rates of serious adverse events were low across all the studies and these were all related to either sepsis or hematuria requiring return to theater to achieve endoscopic control. Late complications have been rare and include bladder neck contracture as reported in two studies. ${ }^{13,14}$ 
Table 3 Selection Criteria of Included Studies

\begin{tabular}{|c|c|c|}
\hline Author & Inclusion & Exclusion \\
\hline Dixon ${ }^{9}$ & NR & $\begin{array}{l}\text { - Bladder or sphincter abnormalities } \\
\text { - Penile prosthesis, } \\
\text { - Prior surgery for BPH } \\
\text { - Confirmed or suspected prostate cancer } \\
\text { - Prior radiation } \\
\text { - Urethral strictures } \\
\text { - Recent prostate biopsy (30 days) }\end{array}$ \\
\hline Mynderse ${ }^{10}$ & NR & NR \\
\hline Dixon"l & $\begin{array}{l}\text { - } \geq 45 \text { years } \\
\text { - } \text { Prostate volume } 20-120 \mathrm{cc}, \\
\text { - } \text { IPSS } \geq 13 \\
\text { - } \mathrm{Q}_{\max } \leq 15 \mathrm{~mL} / \mathrm{s}, \\
\text { - } \mathrm{PVR}<300 \mathrm{~mL} \text {. } \\
\text { - } \text { Median lobe included }\end{array}$ & $\begin{array}{l}\text { - Prior surgery for BPH } \\
\text { - Confirmed or suspected prostate or bladder } \\
\text { cancer } \\
\text { - Active UTI }\end{array}$ \\
\hline Darson $^{12}$ & No standardized protocol (median lobe included) & No standardized protocol \\
\hline Mollengarden ${ }^{13}$ & Clinical judgement of surgeon & NR \\
\hline Bole ${ }^{15}$ & NR & NR \\
\hline Johnston ${ }^{16}$ & NR & NR \\
\hline Tutrone $^{17}$ & - Prostate volume $30-80 \mathrm{cc}$. & No exclusion \\
\hline Mcvary ${ }^{18}$ & - Catheter dependent patients & NR \\
\hline Siena ${ }^{20}$ & $\begin{array}{l}\text { - }>18 \text { years } \\
\text { No prior surgery for BPH, International Prostate Symptom Score (IPSS) } \geq \\
\text { 13, peak urinary flow rate }(\mathrm{Qmax}) \leq 15 \mathrm{~mL} / \mathrm{sec} \text { with minimum voided } \\
\text { volume of } \geq 125 \mathrm{~mL} \text {, post-void residual } \leq 250 \mathrm{~mL} \text {, prostate volume }>30 \text { and } \\
\leq 120 \mathrm{cc} \text {. }\end{array}$ & NR \\
\hline Mcvary ${ }^{14}$ & $\begin{array}{l}\text { - } \geq 50 \text { years } \\
\text { - IPSS } \geq 13 \text {, } \\
\text { - Prostate volume } 3080 \mathrm{cc} \text {, } \\
\text { - } \text { PVRax of } \leq 15 \mathrm{~mL} / \mathrm{s} \\
\text { PVRine }<250 \mathrm{~mL}\end{array}$ & $\begin{array}{l}\text { - PSA }>2.5 \mathrm{ng} / \mathrm{mL} \text { with a free PSA }<25 \% \text { unless } \\
\text { prostate cancer was ruled out by biopsy } \\
\text { - Active urinary tract infection }\end{array}$ \\
\hline Garden 19 & NR & NR \\
\hline
\end{tabular}

Abbreviations: IPSS, international prostate symptom score; Qmax, maximum urinary flow rate; UTI, urinary tract infection; NR, not reported.

No study recorded late complication rate above $5 \%$. No deaths were recorded across any of the studies.

Re-treatment rates also appear low although only a single study has achieved follow up to five years where the rate was $4.4 \% .^{14}$ The range of re-treatment rates reported at 12 month follow up was $0.95 \%$ to $8.33 \%$. In contrast, the re-treatment rate at five years reported in the LIFT study was $13.6 \%{ }^{24}$ Tolerability and patient satisfaction appear favorable. Johnston et al reported that $91 \%$ of patients would be prepared to go through repeat Rezum procedure if ultimately required. ${ }^{16}$

\section{Sexual Dysfunction}

Six studies reported on incidence of de-novo sexual dysfunction occurring post treatment. ${ }^{11-14,16,19}$ Three of these reported no new cases. ${ }^{11,12,14}$ New onset erectile dysfunction $(3.1 \%)$ was reported by Mollengarden et al and only in one other study. ${ }^{13,19}$ Two studies revealed cases of retrograde ejaculation, however, rates were noticeably low $(<6 \%){ }^{13,16}$ Gupta et al compared outcomes of randomized trial 3 year follow up data with the Medical Therapy of Prostatic Symptoms (MTOPS) study (n=1209) in order to determine if either pharmacotherapy or a single 
Table 4 Clinical Outcomes of the Included Studies

\begin{tabular}{|c|c|c|c|c|c|c|c|c|c|}
\hline Author & \multicolumn{2}{|c|}{$\begin{array}{l}\text { Mean \% Change } \\
\text { in IPSS }\end{array}$} & \multicolumn{2}{|c|}{$\begin{array}{l}\text { Mean \% Change } \\
\text { in Qmax }\end{array}$} & $\begin{array}{l}\text { Mean \% Change in } \\
\text { Prostate Volume }\end{array}$ & $\begin{array}{l}\text { Mean } \\
\text { Change in } \\
\text { PSA }\end{array}$ & $\begin{array}{l}\text { Mean \% } \\
\text { Change in } \\
\text { QoL }\end{array}$ & \multicolumn{2}{|c|}{$\begin{array}{l}\text { Mean Change } \\
\text { in IIEF } 5(\%)\end{array}$} \\
\hline Dixon 9 & \multicolumn{2}{|l|}{ NR } & \multicolumn{2}{|l|}{ NR } & NR & $N R$ & NR & \multicolumn{2}{|l|}{ NR } \\
\hline Mynderse ${ }^{10}$ & \multicolumn{2}{|l|}{ NR } & \multicolumn{2}{|l|}{ NR } & -28.9 & -0.2 & NR & \multicolumn{2}{|l|}{ NR } \\
\hline Dixon" & \multicolumn{2}{|l|}{$-58.5^{*}$} & \multicolumn{2}{|l|}{$+44.6 *$} & $-30^{*}$ & NR & $+59 *$ & \multicolumn{2}{|l|}{+30.5} \\
\hline Darson $^{12}$ & \multicolumn{2}{|l|}{$-45.2^{*}$} & \multicolumn{2}{|l|}{+51.4} & -34.9 & NR & $-37.8^{*}$ & \multicolumn{2}{|l|}{$N R$} \\
\hline Mollengarden ${ }^{13}$ & \multicolumn{2}{|l|}{$-60.0^{*}$} & \multicolumn{2}{|l|}{$+71.7^{*}$} & $-17.9^{*}$ & -0.33 & NR & \multicolumn{2}{|l|}{ NR } \\
\hline \multirow[t]{2}{*}{ Bole ${ }^{15}$} & $<80 \mathrm{cc}$ & $\geq 80 \mathrm{cc}$ & $<80 \mathrm{cc}$ & $\geq 80 \mathrm{cc}$ & \multirow[t]{2}{*}{ NR } & \multirow[t]{2}{*}{ NR } & \multirow[t]{2}{*}{ NR } & \multirow{2}{*}{\multicolumn{2}{|c|}{ NR }} \\
\hline & $-45^{*}$ & $\begin{array}{l}-39 \\
0.04\end{array}$ & $\begin{array}{l}+40.2 \\
0.001\end{array}$ & $\begin{array}{l}+65 \\
0.002\end{array}$ & & & & & \\
\hline Johnston ${ }^{16}$ & \multicolumn{2}{|l|}{$-78.9 *$} & \multicolumn{2}{|l|}{$+97 *$} & $-33^{*}$ & NR & $+72 *$ & \multicolumn{2}{|l|}{$+26 *$} \\
\hline Tutrone $^{17}$ & \multicolumn{2}{|l|}{ NR } & \multicolumn{2}{|l|}{ NR } & -33.3 & NR & NR & \multicolumn{2}{|l|}{ NR } \\
\hline Mcvary $^{18}$ & \multicolumn{2}{|l|}{ NR } & \multicolumn{2}{|l|}{ NR } & NR & NR & NR & \multicolumn{2}{|l|}{ NR } \\
\hline Siena ${ }^{20}$ & \multicolumn{2}{|l|}{$-79.5 \%$} & \multicolumn{2}{|l|}{$N R$} & NR & NR & NR & \multicolumn{2}{|l|}{+17} \\
\hline Mcvary ${ }^{14}$ & \multicolumn{2}{|l|}{$-48^{*}$} & \multicolumn{2}{|l|}{$+49 *$} & NR & -2.5 & $45^{*}$ & 7.6 & \\
\hline Garden $^{19}$ & $<80 \mathrm{cc}$ & $\geq 80 \mathrm{cc}$ & $<80 \mathrm{cc}$ & $\geq 80 \mathrm{cc}$ & NR & NR & NR & $<80 \mathrm{cc}$ & $\geq 80 \mathrm{cc}$ \\
\hline & -32.4 & -22.2 & $+15 . \%$ & $+98 *$ & & & & NR & +8.6 \\
\hline
\end{tabular}

Note: *Statistically significant $(p<0.05)$.

Abbreviation: NR, not reported.

surgical intervention (Rezum) caused more deterioration in sexual symptoms among sexually active men. ${ }^{25}$ Their findings concluded that both finasteride and combination therapy resulted in significant reduction in sexual desire as well as worsening of both erectile and ejaculatory function. In contrast, Rezum was not associated with negative impact on any of these domains. Four studies included a validated tool, International Index of Erectile Function (IIEF-5) as part of evaluation of treatment impact. ${ }^{11,14,16,19}$ All of them reported improvements, which ranged from 7.6-30.5\%.

\section{Morphological Changes}

In 2015, Dixon et al reported findings from an early, proof of concept study and performed gadolinium enhanced magnetic resonance imaging (MRI) at one week post surgery. ${ }^{9}$ The mean volume of coalesced lesion was $9.6 \mathrm{~cm}^{3}$ and the largest recorded in the series was $35.1 \mathrm{~cm}^{3}$. More recently, Mynderse et al enrolled 45 patients to also undergo regular imaging surveillance with MRI. ${ }^{10}$ Early imaging at one week post procedure revealed similar results. The mean volume of the coalesced lesion created was $8.2 \mathrm{~cm}^{3}\left(0.5-24.0 \mathrm{~cm}^{3}\right)$. At 6 months follow up, the mean reduction in volume of prostate was $-28.9 \%$ and $-38 \%$ in the transition zone. Three further studies have reported greater than $30 \%$ reduction in prostate volume. ${ }^{12,16,17}$ The lack of specimen retrieval does represent a disadvantage of Rezum and as a consequence no histopathological analysis is possible. Little is known currently regarding interpretation of PSA values post Rezum treatment in regard to evaluation for possible prostate cancer. There is also a lack of data on impact of Rezum treatment on later surgery for both BPH and prostate cancer.

\section{Cost}

None of the included studies provided information regarding cost of Rezum. However, a recent cost effectiveness analysis by Ulchacker et al offers an early insight into the economic status of this device, which is favorable. ${ }^{26}$ The cost for Rezum was given as \$2489 (US), which includes cost for pre-operative assessment 


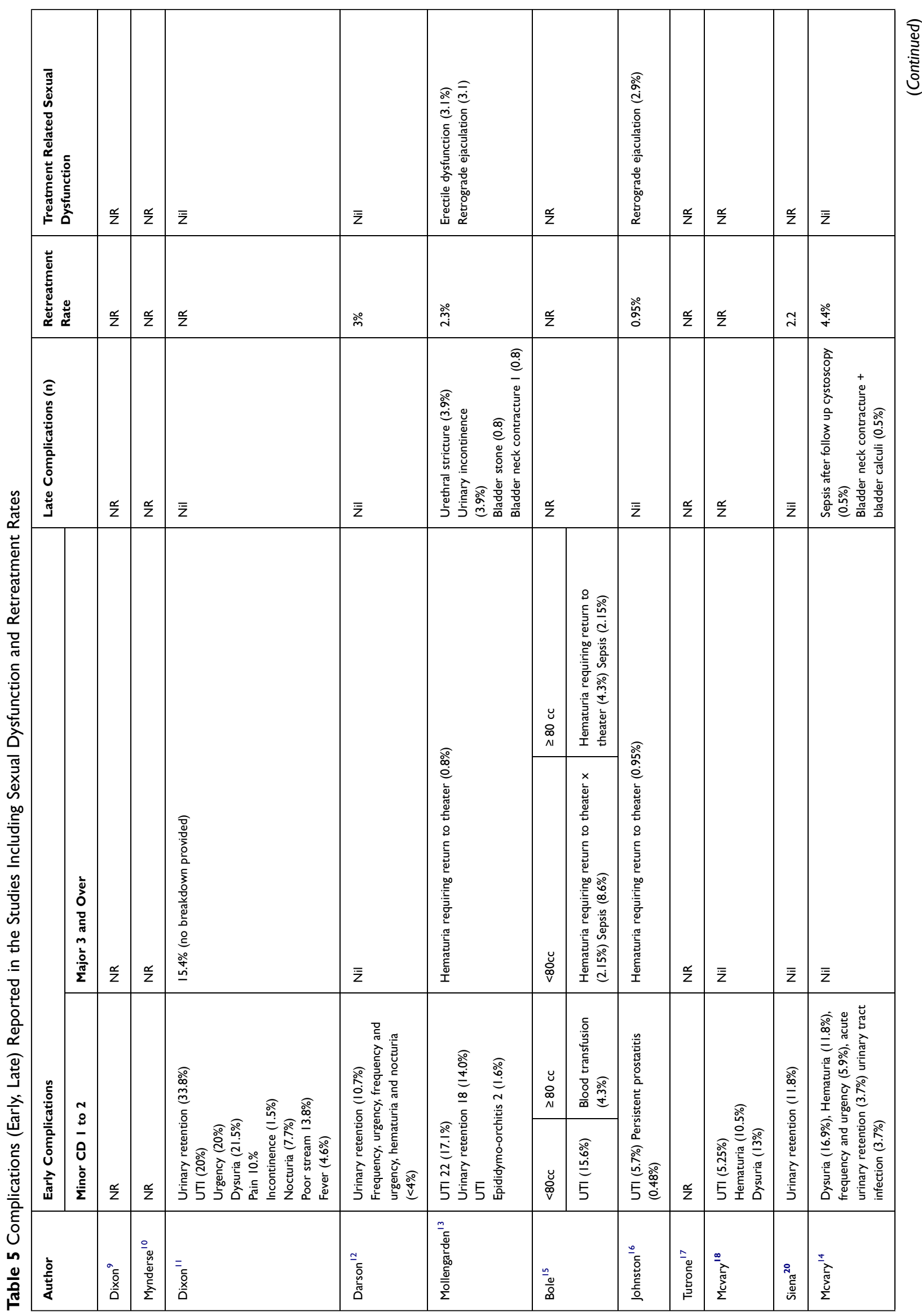




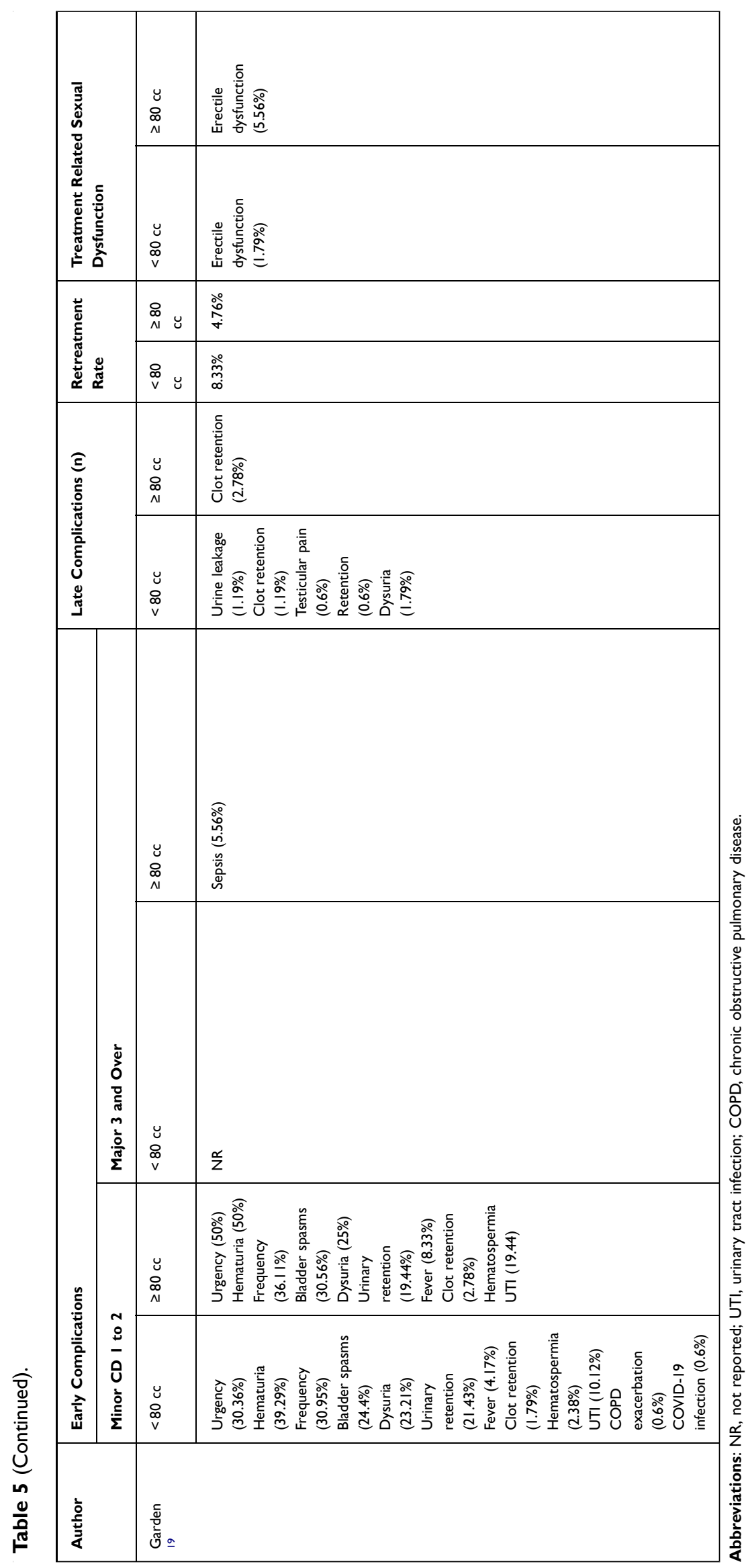


with cystoscopy, transrectal ultrasound (TRUS) and urodynamic study (UDS) as well as post-operative assessment and one year follow up appointment. This was cheaper than for TURP (\$4821), although their evaluation determined inferiority of clinical outcomes achieved with Rezum compared to TURP. However, when stratified according to outcomes based on cost, these two interventions were aligned and were the most cost-effective treatments compared to both branded and generic combination therapy ( $5 \alpha$-reductase inhibitor $+\alpha$-blocker), urolift and greenlight procedure. Cost modeling data reported by NICE, estimate that over a four-year period, Rezum is able to provide savings of $£ 569$ and $£ 651$ compared to TURP and holmium laser enucleation of the prostate (HoLEP) respectively. ${ }^{8}$ It is difficult to know if these projected savings are realistic due to expert evaluations largely relying on the randomized trial data as it is the only study to achieve four year follow up to date. The key driver for this cost saving when compared with such other standard BPH treatments, relies on the provision of Rezum as a day case surgery procedure. Length of stay and therefore determination of success at performing Rezum as a day case procedure was poorly reported across the studies and therefore it is difficult to truly evaluate the feasibility of establishing a day case service. A fundamental component of why it can be done as an ambulatory procedure is the lack of general anesthetic and even intravenous sedation required. However, outside of the trial context, most units appeared to carry out Rezum under general anesthetic, at least in the early period. Therefore, there remains a lack of real-world data providing evidence of this nature.

\section{Limitations and Further Limitations}

While there has been a recent surge in studies on Rezum, which all deliver promising early results, there is a lack of randomized trial data. Future studies, which compare against other standard BPH surgeries are warranted as at present only one sham study exists in world literature. The Comparing uroLift Experience Against Rezum (CLEAR) study, a randomized trial, is currently ongoing. Caution should also be noted when interpreting these early results as in the setting of both pilot studies and clinical trials, inclusion/exclusion criteria can be very strict when in reality the demographics of patients who present in clinic and require surgical intervention for BPH are typically much broader. Standardized evaluation parameters will aid future evaluation of Rezum's efficacy. To date, no studies have formally assessed the learning curve for the procedure. However, expert opinion (Level $\mathrm{V}$ evidence) has highlighted that it is straight forward for those with sufficient endoscopic experience.

\section{Conclusion}

Current evidence regarding Rezum demonstrates that it holds a strong efficacy and safety profile. While low grade side effects such as self-resolving bothersome LUTS appear to be present in up to one third of patients, serious adverse events seldom appear. Lack of or minimal de-novo sexual dysfunction appears to be consistently maintained across all evidence available and represents a further advantage of this procedure. Future studies with intervention comparators and longer follow up will provide important data to help delineate its formal position in the treatment algorithm as well as establish the patient profile most suitable for this particular surgery.

\section{Disclosure}

The authors report no conflicts of interest in this work.

\section{References}

1. Speakman M, Kirby R, Doyle S, Ioannou C. Burden of male lower urinary tract symptoms (LUTS) suggestive of benign prostatic hyperplasia (BPH) - focus on the UK. BJU Int. 2015;115(4):508-519. PMID: 24656222. doi:10.1111/bju. 12745

2. Lee SWH, Chan EMC, Lai YK. The global burden of lower urinary tract symptoms suggestive of benign prostatic hyperplasia: a systematic review and meta-analysis. Sci Rep. 2017. 7(1):7984. doi:10.1038/s41598-017-06628-8. PMID: 28801563. PMCID: PMC5554261.

3. Pinto JD, He HG, Chan SW, Wang W. Health-related quality of life and psychological well-being in men with benign prostatic hyperplasia: an integrative review. Jpn J Nurs Sci. 2016;13(3):309-323. PMID: 26782969. doi:10.1111/jjns.12115

4. Christidis D, McGrath S, Perera M, Manning T, Bolton D, Lawrentschuk N. Minimally invasive surgical therapies for benign prostatic hypertrophy: the rise in minimally invasive surgical therapies. Prostate Int. 2017. 2:41-46. doi:10.1016/j. prnil.2017.01.007. PMID: 28593165. PMCID: PMC5448728.

5. Jones P, Rai BP, Aboumarzouk O, Somani BK. UroLift: a new minimally-invasive treatment for benign prostatic hyperplasia. Ther Adv Urol. 2016. 6:372-376. doi:10.1177/1756287216671497. PMID: 27904652. PMCID: PMC5117169.

6. Carnevale FC, Iscaife A, Yoshinaga EM, Moreira AM, Antunes AA, Srougi M. Transurethral Resection of the Prostate (TURP) Versus Original and PErFecTED Prostate Artery Embolization (PAE) Due to Benign Prostatic Hyperplasia (BPH): preliminary results of a single center, prospective, urodynamic-controlled analysis. Cardiovasc Intervent Radiol. 2016;39(1):44-52. PMID: 26506952. doi:10.1007/ s00270-015-1202-4

7. Jones P, Rai BP, Nair R, Somani BK. Current status of prostate artery embolization for lower urinary tract symptoms: review of world literature. Urology. 2015;86(4):676-681. [PMID: 26238328.]. doi:10.1016/j.urology.2015.05.011 
8. Westwood J, Geraghty R, Jones P, Rai BP, Somani BK. Rezum: a new transurethral water vapour therapy for benign prostatic hyperplasia. Ther Adv Urol. 2018. 10(11):327-333. doi:10.1177/ 1756287218793084. PMID: 30344644. PMCID: PMC6180381.

9. Rezum for treating lower urinary tract symptoms secondary to benign prostatic hyperplasia. Medical technologies guidance [MTG49]. Available from: https://www.nice.org.uk/guidance/mtg49. Accessed July 2, 2021.

10. Dixon CM, Rijo Cedano E, Mynderse LA, Larson TR. Transurethral convective water vapor as a treatment for lower urinary tract symptomatology due to benign prostatic hyperplasia using the Rezūm( $\left.{ }^{(\mathbb{R}}\right)$ system: evaluation of acute ablative capabilities in the human prostate. Res Rep Urol. 2015;7:13-18. doi:10.2147/RRU.S74040. PMID: 25674555. PMCID: PMC4321608.

11. Mynderse LA, Hanson D, Robb RA, et al. Rezūm system water vapor treatment for lower urinary tract symptoms/benign prostatic hyperplasia: validation of convective thermal energy transfer and characterization with magnetic resonance imaging and 3-dimensional renderings. Urology. 2015;86(1):122-127. PMID: 25987496. doi:10.1016/j.urology.2015.03.021

12. Dixon CM, Cedano ER, Pacik D, et al. Two-year results after convective radiofrequency water vapor thermal therapy of symptomatic benign prostatic hyperplasia. Res Rep Urol. 2016;8:207-216. doi:10.2147/RRU.S119596

13. Darson MF, Alexander EE, Schifman ZJ, et al. Procedural techniques and multicenter postmarket experience using minimally invasive convective radiofrequency thermal therapy with Rezūm system for treatment of lower urinary tract symptoms due to benign prostatic hyperplasia. Res Reports Urol. 2017;9:159-168. doi:10.2147/RRU.S143679

14. Mollengarden D, Goldberg K, Wong D, Roehrborn C. Convective radiofrequency water vapor thermal therapy for benign prostatic hyperplasia: a single office experience. Prostate Cancer Prostatic Dis. 2018;21 (3):379-385. PMID: 29282358. doi:10.1038/s41391-017-0022-9

15. McVary KT, Gittelman MC, Goldberg KA, et al. Final 5-year outcomes of the multicenter randomized sham-controlled trial of rezūm water vapor thermal therapy for treatment of moderate-to-severe lower urinary tract symptoms secondary to benign prostatic hyperplasia. J Urol. 2021;19. doi:10.1097/JU.0000000000001778. PMID: 33872051

16. Bole R, Gopalakrishna A, Kuang R, et al. Comparative postoperative outcomes of rezūm prostate ablation in patients with large versus small glands. J Endourol. 2020;34(7):778-781. PMID: 32408768. doi:10.1089/end.2020.0177
17. Johnston MJ, Noureldin M, Abdelmotagly Y, et al. Rezum water vapour therapy: promising early outcomes from the first UK series. BJU Int. 2020;126(5):557-558. PMID: 32777175. doi:10.1111/bju.15203

18. Tutrone RF, Schiff W. Early patient experience following treatment with the UroLift prostatic urethral lift and Rezum steam injection. Can J Urol. 2020;27(3):10213-10219. PMID: 32544043.

19. McVary KT, Holland B, Beahrs JR. Water vapor thermal therapy to alleviate catheter-dependent urinary retention secondary to benign prostatic hyperplasia. Prostate Cancer Prostatic Dis. 2020;23 (2):303-308. doi:10.1038/s41391-019-0187-5. PMID: 31740738. PMCID: PMC7237346.

20. Garden EB, Shukla D, Ravivarapu KT, et al. Rezum therapy for patients with large prostates $(\geq 80 \mathrm{~g})$ : initial clinical experience and postoperative outcomes. World J Urol. 2021. doi:10.1007/s00345-020-03548-7

21. Siena G, Cindolo L, Ferrari G, et al. Water vapor therapy (Rezūm) for lower urinary tract symptoms related to benign prostatic hyperplasia: early results from the first Italian multicentric study. World J Urol. 2021:1-6. doi:10.1007/s00345-021-03642-4. PMID: 33787986. PMCID: PMC8010783.

22. Kang TW, Jung JH, Hwang EC, Borofsky M, Kim MH, Dahm P. Convective radiofrequency water vapour thermal therapy for lower urinary tract symptoms in men with benign prostatic hyperplasia. Cochrane Database Syst Rev. 2020. 3(3):CD013251. doi:10.1002/ 14651858.CD013251.pub2. PMID: 32212174. PMCID: PMC7093307.

23. Gratzke C, Bachmann A, Descazeaud A, et al. EAU guidelines on the assessment of non-neurogenic male lower urinary tract symptoms including benign prostatic obstruction. Eur Urol. 2015;67:1099-1109. doi:10.1016/j.eururo.2014.12.038

24. Roehrborn CG, Barkin J, Gange SN, et al. Five year results of the prospective randomized controlled prostatic urethral L.I.F.T. study. Can J Urol. 2017;24(3):8802-8813. PMID: 28646935.

25. Gupta N, Rogers T, Holland B, Helo S, Dynda D, McVary KT. Three-year treatment outcomes of water vapor thermal therapy compared to doxazosin, finasteride and combination drug therapy in men with benign prostatic hyperplasia: cohort Data from the MTOPS Trial. J Urol. 2018;200 (2):405-413. PMID: 29499208. doi:10.1016/j.juro.2018.02.3088

26. Ulchaker JC, Martinson MS. Cost-effectiveness analysis of six therapies for the treatment of lower urinary tract symptoms due to benign prostatic hyperplasia. Clinicoecon Outcomes Res. 2017;10:29-43. doi:10.2147/ CEOR.S148195. PMID: 29343977. PMCID: PMC5749396.

\section{Publish your work in this journal}

Research and Reports in Urology is an international, peer-reviewed, open access journal publishing original research, reports, editorials, reviews and commentaries on all aspects of adult and pediatric urology in the clinic and laboratory including the following topics: Pathology, pathophysiology of urological disease; Investigation and treatment of urological disease; Pharmacology of drugs used for the treatment of urological disease. The manuscript management system is completely online and includes a very quick and fair peer-review system, which is all easy to use. Visit http://www.dovepress.com/ testimonials.php to read real quotes from published authors. 